\title{
Rapid automated method for on-site determination of sulfadiazine in fish farming: a stainless steel veterinary syringe coated with a selective membrane of PVC serving as a potentiometric detector in a flow-injection-analysis system
}

\author{
S. A. A. Almeida \& L. R. Amorim \& A. H. Heitor \& \\ M. C. B. S. M. Montenegro \& J. Barbosa \& L. C. Sá \& \\ M. G. F. Sales
}

\begin{abstract}
Sulfadiazine is an antibiotic of the sulfonamide group and is used as a veterinary drug in fish farming. Monitoring it in the tanks is fundamental to control the applied doses and avoid environmental dissemination. Pursuing this goal, we included a novel potentiometric design in a flow-injection assembly. The electrode body was a stainless steel needle veterinary syringe of $0.8-\mathrm{mm}$
\end{abstract}

inner diameter. A selective membrane of PVC acted as a sensory surface. Its composition, the length of the electrode, and other flow variables were optimized. The best performance was obtained for sensors of $1.5-\mathrm{cm}$ length and a membrane composition of $33 \%$ PVC, $66 \% o-$ nitrophenyloctyl ether, $1 \%$ ion exchanger, and a small amount of a cationic additive. It exhibited Nernstian slopes of $61.0 \mathrm{mV}$ decade ${ }^{-1}$ down to $1.0 \times 10^{-5} \mathrm{~mol} \mathrm{~L}^{-1}$, with a limit of detection of $3.1 \times 10^{-6} \mathrm{~mol} \mathrm{~L}^{-1}$ in flowing media. All

necessary $\mathrm{pH} /$ ionic strength adjustments were performed online by merging the sample plug with a buffer carrier of 4-(2-hydroxyethyl)-1-piperazineethanesulfonic acid, $\mathrm{pH}$ 4.9. The sensor exhibited the advantages of a fast response time (less than $15 \mathrm{~s}$ ), long operational lifetime (60 days), and good selectivity for chloride, nitrite, acetate, tartrate, citrate, and ascorbate. The flow setup was successfully applied to the analysis of aquaculture waters. The analytical results were validated against those obtained with liquid chromatography-tandem mass spectrometry procedures. The sampling rate was about 84 samples per hour and recoveries ranged from 95.9 to $106.9 \%$.

Keywords

Sulfadiazine, Chemical sensor, Aquaculture, Flowinjection analysis, Potentiometry

Introduction

Sulfadiazine (SDZ) is one of the sulfonamides most used [1] to treat veterinary and human infections. Its wide use in animal feed makes it a serious contaminant in food of 
animal origin, posing serious problems to human health, such as allergic or toxic reactions [2] and the appearance of resistant bacteria [3-5]. This may be prevented by avoiding, first, its environmental dissemination and, later, its entry into the food chain.

Aquaculture activities are an important vehicle for dissemination of SDZ throughout the environment. The first measure to prevent spread of this drug is to have strict control of the applied doses by monitoring the waters from the tanks where the fish are being farmed. As the SDZ concentration may change with time (reaching several consecutive days of administration), monitoring these concentrations in real time is fundamental. This requires specific instrumental setups that allow monitoring of the drug online and in a continuous fashion. This must be achieved with a low-cost method, providing quick and selective responses.

Many papers may be found in the literature concerning SDZ determination in fish and feed [6-8]. Liquid chromatography with tandem mass spectrometry (LC-MS/MS) is currently regarded as the tool of choice for analysis of antibiotic residues in animal-derived food [6]. The use of LC-MS/MS also has the advantage of providing structural information. By contrast, only a few methods have been reported for monitoring SDZ in surface waters [2] or wastewaters [9]. These also rely on high-performance liquid chromatography, which is unsuitable for establishing continuous monitoring of SDZ in local fish farming units. For this purpose, rapid and inexpensive screening methods relying on more or less selective sensory surfaces are desired. The practical implementation of this idea requires low-cost equipment that is easy to operate.

Sensors relying on immunoassays $[10,11]$ are quite effective but are quite expensive for routine and continuous monitoring. Chemical sensors relying on charged and neutral carriers are also effective and have been proposed $[12,13]$. Both sensors offer suitable analytical features for conducting continuous analysis of the administered drug, ion exchangers being much less expensive sensory materials than neutral/charged carriers.

Chemical sensors may also be a suitable methodological approach for monitoring SDZ on-site by means of flow-injection analysis (FIA). This association combines and enhances the advantages of both and avoids some of the limitations of potentiometric sensors [14]. The transient nature of the FIA signal may help overcome the effect of interfering ions on the sensors (if the response to these ions is slower than that of the target analyte) and the lifetime of the electrodes may be extended as the sensor surface is predominantly exposed to carrier solution $[15,16]$.

The performance of flow-injection potentiometric techniques depends largely on the design of flow-through potentiometric cells. Traditionally, potentiometric sensors are conceived with an internal solution, which is a source of sample contamination. Even when this effect is minimized [17], the internal reference hinders the development of miniaturized devices. Solid-contact electrodes should be employed instead [18], where the membrane materials are cast over conductive solid surfaces. When flowing conditions are used, the solid-contact electrodes should have a tubular shape. This configuration avoids the disturbance of the laminar flow and reduces the response time.

This work describes the construction of SDZ-selective electrodes made from stainless steel syringes (with tubular shape) of different lengths. The selective membrane coated the internal surface of the needle and the stainless steel acted as a solid contact. The analytical performance was evaluated in a FIA system and compared with the analytical performances of graphitebased solid-contact electrodes of conventional and tubular shapes. The flow assembly was optimized and applied to the analysis of aquaculture waters.

\section{Experimental}

\section{Apparatus}

Potentiometric measurements were made in an

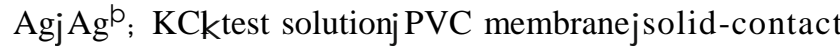
conductive material electrochemical cell. The emf was measured with a Crison $\mu \mathrm{pH} 2002$ potentiometer $( \pm 0.1-\mathrm{mV}$ sensitivity) coupled to a Kipp \& Zonen BD 111 recorder. The reference electrode was an Orion 90-00-29 doublejunction electrode.

The FIA system (Fig. 1) consisted of a Gilson Minipuls 3 peristaltic pump with PVC tubing (1.60 and/ or $2.00 \mathrm{~mm}$ inner diameter) and a four-way Rheodyne 5020 injection valve. All components were joined by polytetrafluoroethylene tubing (Omnifit, Teflon, 0.8-mm inner diameter) and Gilson end fittings and connectors. Support devices for tubular and reference electrodes and the confluence point were constructed from Perspex as reported in [12].

The potentiometric data were validated against data obtained using the LC-MS/MS procedure. Measurements were made with an Agilent Technologies (Palo Alto, CA, USA) 1100 series liquid chromatography setup, equipped with a mass-selective detector, quaternary pump with vacuum degasser, autosampler, and thermostatic column compartment coupled to a Sciex API 2000 (Applied Biosystems, Foster City, USA) triple-quadruple system. The liquid chromatography system was equipped with a Zorbax Eclipse XDB $\mathrm{C}_{18}, 5 \mu \mathrm{m}, 150 \mathrm{~mm} \times 2.1 \mathrm{~mm}$ column (Agilent Technologies, Palo Alto, USA). 
Fig. 1 Flow-injection-analysis system with tubular electrodes. SDZ sulfadiazine

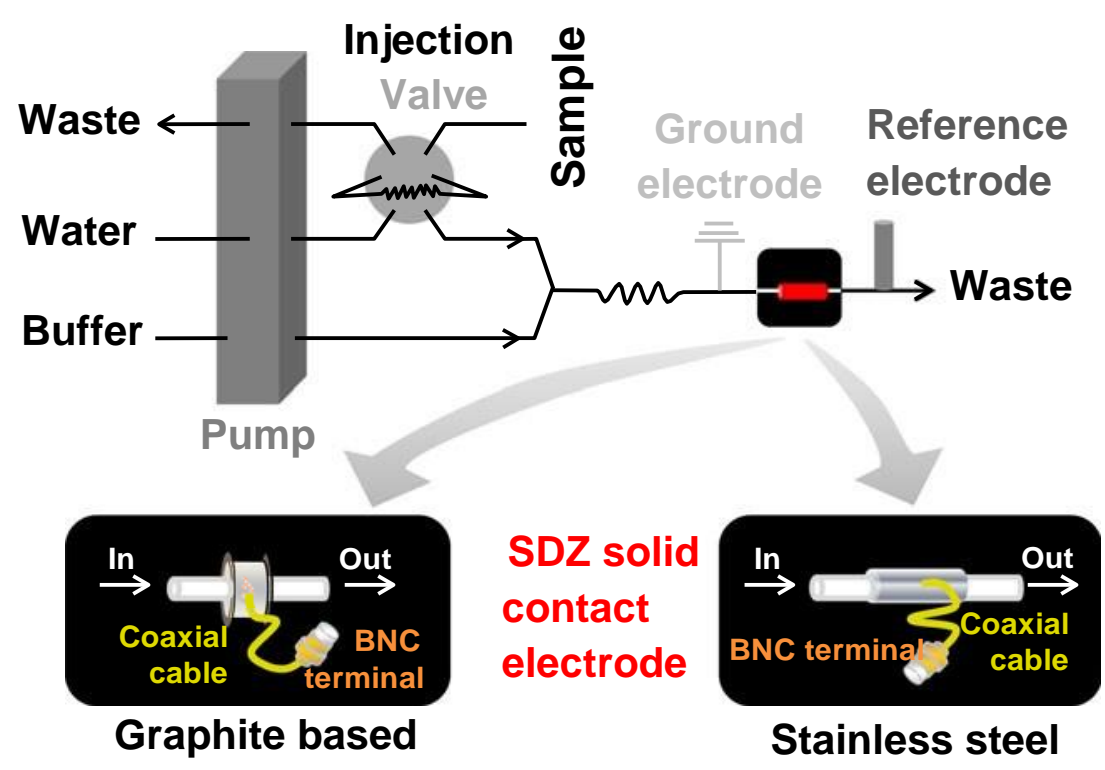

Reagents and solutions

All chemicals were of analytical grade and deionized water (conductivity less than $0.1 \mu \mathrm{S} \mathrm{cm}{ }^{-1}$ ) was used throughout. Sodium SDZ (NaSDZ; Sigma), bis(triphenylphosphoranylidene)ammonium chloride (BTPPIACl; Aldrich), $o$-nitrophenyl octyl ether (oNPOE; Fluka), dibutylphthalate (DBP; Fluka), tetraoctylammonium bromide (TOABr; Sigma), 4tert-octylphenol (TOP; Fluka), PVC (Fluka) of high molecular weight, tetrahydrofuran (Riedel-de Haën), and 4(2-hydroxyethyl)-1-piperazineethanesulfonic acid (HEPES; Sigma) were used in this work.

The most concentrated SDZ standard solution had a concentration of $1.0 \times 10^{-2} \mathrm{~mol} \mathrm{~L}^{-1}$. It was prepared by dissolving about $1.2 \mathrm{~g}$ of $\mathrm{NaSDZ}$ in $500.0 \mathrm{~mL}$ of $0.01 \mathrm{~mol} \mathrm{~L}^{-1}$ HEPES $(\mathrm{pH} \sim 4.9)$ or in water. These standards were used in batch or flow assays, respectively. Less concentrated SDZ standards were prepared by suitable dilution of the previous solution in the same solvent.

The evaluation of the effect of $\mathrm{pH}$ and other interfering species required sodium hydroxide (Merck), concentrated sulfuric acid (Merck), sodium chloride (Merck), sodium nitrite (Merck), sodium acetate (Merck), sodium sulfate (Merck), potassium iodide (Aldrich), potassium bromide (Aldrich), sodium citrate (Riedel-de Haën), sodium tartrate (Riedel-de Haën), sodium ascorbate (Aldrich), and chloropromazine hydrochloride (Riedel-de Haën).

\section{Construction of the electrode body}

Graphite-based electrodes were constructed with a conventional shape (similar to $\mathrm{pH}$ electrodes) or a tubular configuration for batch and flow evaluations, respectively [12]. The electrode body was made from Perspex® and had a conductive solid contact prepared with graphite/epoxy resin exposed on one side, and polished prior to membrane coating.

Stainless steel electrodes had a tubular configuration and were made from veterinary syringes $(0.8-\mathrm{mm}$ inner diameter) obtained from local drug stores. The needles were cut transversally to obtain a hollow cylinder of 5-, 10-, or 15$\mathrm{mm}$ length. A shielded electrical wire was connected to the external surface and the remaining conducting external layer of the cylinder was isolated. The membrane solution was applied dropwise in the inner wall of the cylinder in order to coat it. The resulting detection unit was inserted in the flow assembly by placing small pieces of pumping tubes at both ends of the needle.

Preparation of the SDZ-selective electrodes

The anionic exchanger [bis(triphenylphosphoranylidene) ammonium sulfadiazine, BTPPIASDZ] was synthesized by mixing $50.0 \mathrm{~mL}$ of a $1.0 \times 10^{-2} \mathrm{~mol} \mathrm{~L}^{-1} \mathrm{NaSDZ}$ aqueous solution with $100.0 \mathrm{~mL}$ of a $1 \times 10^{-2} \mathrm{~mol} \mathrm{~L}^{-1}$ BTPPIACl aqueous solution. The resulting solid was separated by filtration and thoroughly washed with water. It was dried after under a nitrogen atmosphere and kept in a dessicator.

Sensor solutions were prepared by dissolving about $0.0130 \mathrm{~g}$ of ion exchanger in about $1.0200 \mathrm{~g}$ of oNPOE (type A, B, and C sensors). The selective membranes were obtained by adding $0.0750 \mathrm{~g}$ of PVC (previously dissolved in about $2.0 \mathrm{~mL}$ of tetrahydrofuran) to $0.2 \mathrm{~mL}$ of each sensor. For membranes $\mathrm{B}$ and $\mathrm{C}$, a small amount of $\mathrm{TOABr}$ or TOP, respectively, was added. An additional membrane

equivalent to membrane $\mathrm{B}$, but having DBP instead of oNPOE, was also prepared (type D sensor). Each of the previous membranes was applied on the solid conductive 
support, made of graphite/epoxy resin (conventional and tubular) or stainless steel (tubular shape).

All electrodes were conditioned by soaking them overnight in a $1 \times 10^{-6} \mathrm{~mol} \mathrm{~L}^{-1} \mathrm{SDZ}$ solution before use and were stored in deionized water between daily measurements. For this purpose, the flow devices were inserted in a closed flow circuit filled with conditioning solution.

Flow potentiometric procedures

The flow assembly is shown in Fig. 1. All potentiometric measurements were conducted at room temperature. The main analytical features of the SDZ-selective electrodes were obtained from calibration curves following the IUPAC recommendations $[19,20]$. The emf was measured after stabilization to $\pm 0.2 \mathrm{mV}$ and was plotted as a function of the logarithm of the SDZ concentration. All analytical signals were measured for increasing concentrations of SDZ, both in batch and in flow assays.

FIA assays were conducted similarly to batch evaluations. The selectivity was assessed by the separated solutions method [21], injecting separately into the FIA system solutions of SDZ or other possible interfering species. The effect of $\mathrm{pH}$ was evaluated by injecting a $1.0 \times 10^{-3} \mathrm{~mol} \mathrm{~L}^{-1} \mathrm{SDZ}$ solution prepared in water. A small adaptation of the manifold, consisting of a closed loop with continuous circulation of $200 \mathrm{~mL}$ of standard solution [22], was required for this purpose. Small amounts of a saturated sodium hydroxide solution were added to provide a $\mathrm{pH}$ increase up to $\mathrm{pH} 12$. This was followed by the addition of small volumes of concentrated sulfuric acid until $\mathrm{pH} 2$ was reached. This $\mathrm{pH}$ was monitored by a second potentiometric cell consisting of a combined glass electrode connected to another $\mathrm{pH}$ meter. Operational $\mathrm{pH}$ ranges were defined for maximum potential variations of $\pm 15 \mathrm{mV}$.

\section{Analysis of aquaculture waters}

Potentiometric analysis was conducted on aquaculture water samples. These were collected from several sweet water aquaculture units in the north of Portugal. The samples were spiked with SDZ up to $140 \mu \mathrm{g} \mathrm{mL}^{-1}$, because by the time of collection there was no previous antibiotic application. The analysis was performed after calibration of the potentiometric units.

LC-MS/MS analysis used a binary gradient phase of $0.1 \%$ formic acid (solvent A) and acetonitrile (solvent B). The gradient started with 90:10 solvent A to solvent B, changed linearly to 10:90 solvent A to solvent B in $15 \mathrm{~min}$, and changed back to 90:10 solvent A to solvent B in $1 \mathrm{~min}$, with a total run time of $16 \mathrm{~min}$. The injection volume was set to $5 \mu \mathrm{L}$, the temperature oven was $40{ }^{\circ} \mathrm{C}$ and the flow rate was $0.35 \mathrm{~mL} \mathrm{~min}^{-1}$. The mass spectrometer operated in positive electrospray ionization mode using the TurbolonSpray source. Nitrogen was used as a curtain gas, collision gas and nebulizer gas with flow rates of 7, 4, and $9 \mathrm{Lmin}^{-1}$. The ion source block temperature was set to $450{ }^{\circ} \mathrm{C}$, and the electrospray capillary voltage was set to $5.0 \mathrm{kV}$. Data acquisition was performed in the multiple reaction monitoring mode.

\section{Results and discussion}

\section{Selection of membrane materials}

Selective membranes include a plasticizer and active ingredients, such as ionophores and ionic additives, in an inert matrix. The inert matrix must be hydrophobic, flexible, nonporous, and crack-resistant and grant the membrane physical-mechanical stability and elasticity. PVC is widely used for this purpose, because it is inexpensive, allows plasticization, and grants good mechanical properties.

The binding between the ionophore and the target ion is the molecular-level event sensed by the potentiometric sensor. Thus, the selected ionophore must have high affinity for SDZ and low ability to leave the membrane for the measuring solution. In this work, BTPPIASDZ was selected as the ionophore. It exchanges negatively charged species (such as SDZ) because it bears a positive charge on the nitrogen atom of a quaternary amine group, but it also bears apolar groups that ensure its long residence in the membrane. Although BTPPIACl has not been widely used for potentiometric sensors, it has been proven to be a suitable material to obtain low limits of linear range, wide dynamic concentration ranges, and long lifetimes [23].

The plasticizer should display high lipophilicity to prevent its exudation from the polymer matrix, and high capacity to dissolve the substrate and other additives [24]. It affects the selectivity of the ion-selective sensor by influencing the extraction of ions into the organic phase and controlling their ion exchange with the ionophore. The nature of the plasticizer influences both the dielectric constant of the membrane and the mobility of the ionophore and its complex [25]. Therefore, the effect of plasticizer type on the response characteristics of the SDZ-selective electrodes was investigated by testing two plasticizers of different polarities: oNPOE and DBP. Their dielectric constants are 23.6 and 6.4, respectively [26].

Ionic additives ensure that ion-selective-electrode (ISE) membranes are permselective, reducing in the present case the cationic interference and lowering the electrical resistance [27]. They may also catalyze the exchange kinetics at the sample/membrane interface. In the present study, $\mathrm{TOABr}$ and TOP were used. They are surfactants with 
polar or cationic heads and $\mathrm{C}_{8}$ apolar chains, being sufficiently lipophilic to remain in the organic membrane phase when in contact with aqueous solution. In terms of analytical performance, the addition of lipophilic additives is expected to enhance the ISE performance, widening the linear range with theoretical slope [27].

Optimization of membrane composition

Several membrane compositions were tested, with about $1 \%$, ion exchanger, $66 \%$ plasticizer, and $33 \%$ PVC. The influence of the nature of the plasticizer and the additive (when present) on the emf was investigated, and the results are shown in Table 1.

\section{Calibration parameters}

All calibrations indicated that BTPPIASDZ was a suitable ion exchanger for SDZ readings and that the additives employed contributed to a major decrease in the lower limit of the linear range, especially when TOP was present. It was also clear that a plasticizer of higher dielectric constant was essential to obtain near-Nernstian behavior.

In general, the best performance was displayed by SDZselective membranes having oNPOE as a plasticizer and TOP as an additive. The corresponding average slope and limit of detection in buffer were $-59.2 \mathrm{mV} \mathrm{decade}^{-1}$ and
$4.0 \times 10^{-6} \mathrm{~mol} \mathrm{~L} \mathrm{~L}^{-1}$, with enhanced reproducibility and repeatability compared with other SDZ sensors.

Response time and lifetime

The time required to achieve a steady potential response ( \pm $2 \mathrm{mV}$ ) for a tenfold increase of SDZ concentration starting at $5 \times 10^{-5} \mathrm{~mol} \mathrm{~L}^{-1}$ was less than $15 \mathrm{~s}$. This indicated that the complexation between SDZ and bis(triphenylphosphoranylidene)ammonium was kinetically fast, which in turn pointed out that the free energy barrier from free to complexed states was small. Replicate calibrations for each sensor indicated low potential drift and long-term stability, especially for type $\mathrm{C}$ sensors.

The proposed electrodes could be used for at least 2 months without any considerable change in the typical response, this being the maximum period observed. Detection limits, response times, linear ranges, and calibration slopes were reproducible within $\pm 3 \%$ of their original values over this period.

\section{Effect of $\mathrm{pH}$}

Reilley diagrams for a $1.0 \times 10^{-3} \mathrm{~mol} \mathrm{~L}^{-1} \mathrm{SDZ}$ solution prepared in water are presented in Fig. 2. The Useful pH ranges always corresponded to acidic media. Increasing the $\mathrm{pH}$ (towards the alkaline range) led to decreasing emfs.
Table 1 Analytical features of conventional sulfadiazine (SDZ) graphite solid-contact electrodes

$I S E$ ion-selective electrode, BTPPIASDZ bis(triphenylphosphoranylidene)ammonium sulfadiazine, $o N P O E$ o-nitrophenyl octyl ether, $D B P$ dibutylphthalate, $\mathrm{TOABr}$ tetraoctylammonium bromide, TOP 4-tertoctylphenol, $L O D$ limit of detection, $L L L R$ lower limit of linear range

${ }^{\mathrm{a}}$ Relative standard deviation for 18 determinations with two different units

${ }^{\mathrm{b}}$ Tested with $5.2 \times 10^{-4} \mathrm{~mol} \mathrm{~L}^{-1}$

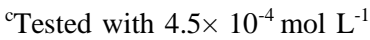

${ }^{\mathrm{d}}$ For a potential change of $\pm 10 \mathrm{mV}$

\begin{tabular}{|c|c|c|c|c|}
\hline Characteristics & ISE A & ISE B & ISE C & ISE D \\
\hline Ionophore & BTPPIASDZ & BTPPIASDZ & BTPPIASDZ & BTPPIASDZ \\
\hline Plasticizer & oNPOE & oNPOE & oNPOE & DBP \\
\hline Additive & - & TOABr & TOP & TOP \\
\hline \multicolumn{5}{|c|}{ Ionic strength adjuster $\left(1 \times 10^{-2} \mathrm{~mol} \mathrm{~L}^{-1}\right)$} \\
\hline $\mathrm{LOD}\left(\mathrm{mol} \mathrm{L}^{-1}\right)$ & $1.6 \times 10^{-4}$ & $1.1 \times 10^{-5}$ & $7.8 \times 10^{-6}$ & $2.0 \times 10^{-5}$ \\
\hline LIRL $\left(\mathrm{mol} \mathrm{L}^{-1}\right)$ & $5.2 \times 10^{-4}$ & $3.0 \times 10^{-4}$ & $1.2 \times 10^{-5}$ & $4.4 \times 10^{-5}$ \\
\hline Slope $\left(m V \text { decade }^{-1}\right)^{\mathrm{a}}$ & $-20( \pm 10.0 \%)$ & $-51( \pm 4.8 \%)$ & $-53( \pm 3.4 \%)$ & $-49( \pm 4.5 \%)$ \\
\hline Intercept (mV) & -162 & -158 & -162 & -110 \\
\hline$R^{2}$ & $>0.9985$ & $>0.9983$ & $>0.9990$ & $>0.9970$ \\
\hline Repeatability $(\mathrm{mV})^{\mathrm{b}}$ & \pm 1.45 & \pm 1.74 & \pm 0.23 & \pm 1.77 \\
\hline Reproducibility $(\mathrm{mV})^{\mathrm{c}}$ & \pm 1.53 & \pm 1.80 & \pm 0.25 & \pm 1.75 \\
\hline Operational $\mathrm{pH}$ range $\mathrm{d}^{\mathrm{d}}$ & $3.5-7.0$ & $3.5-5.9$ & $4.0-5.5$ & $4.0-5.8$ \\
\hline \multicolumn{5}{|c|}{ Buffer (pH 4.5 and $5.0 \times 10^{-3} \mathrm{~mol} \mathrm{~L}^{-1}$ ionic strength) } \\
\hline $\mathrm{LOD}\left(\mathrm{mol} \mathrm{L}^{-1}\right)$ & $2.0 \times 10^{-4}$ & $1.0 \times 10^{-5}$ & $4.0 \times 10^{-6}$ & $8.0 \times 10^{-6}$ \\
\hline $\operatorname{LIRL}\left(\mathrm{mol} \mathrm{L}^{-1}\right)$ & $5.2 \times 10^{-4}$ & $6.3 \times 10^{-5}$ & $1.0 \times 10^{-5}$ & $1.5 \times 10^{-5}$ \\
\hline Slope $\left(\mathrm{mV} \text { decade }^{-1}\right)^{\mathrm{a}}$ & $-40( \pm 10.3 \%)$ & $-56( \pm 2.6 \%)$ & $-59( \pm 2.5 \%)$ & $-44( \pm 2.7 \%)$ \\
\hline Intercept (mV) & -64 & -149 & -156 & -124 \\
\hline$R^{2}$ & $>0.9942$ & $>0.9950$ & $>0.9989$ & $>0.9935$ \\
\hline Repeatability $(\mathrm{mV})^{\mathrm{b}}$ & \pm 1.45 & \pm 1.74 & \pm 0.23 & \pm 1.77 \\
\hline Reproducibility $(\mathrm{mV})^{\mathrm{c}}$ & \pm 1.53 & \pm 1.80 & \pm 0.25 & \pm 1.75 \\
\hline
\end{tabular}




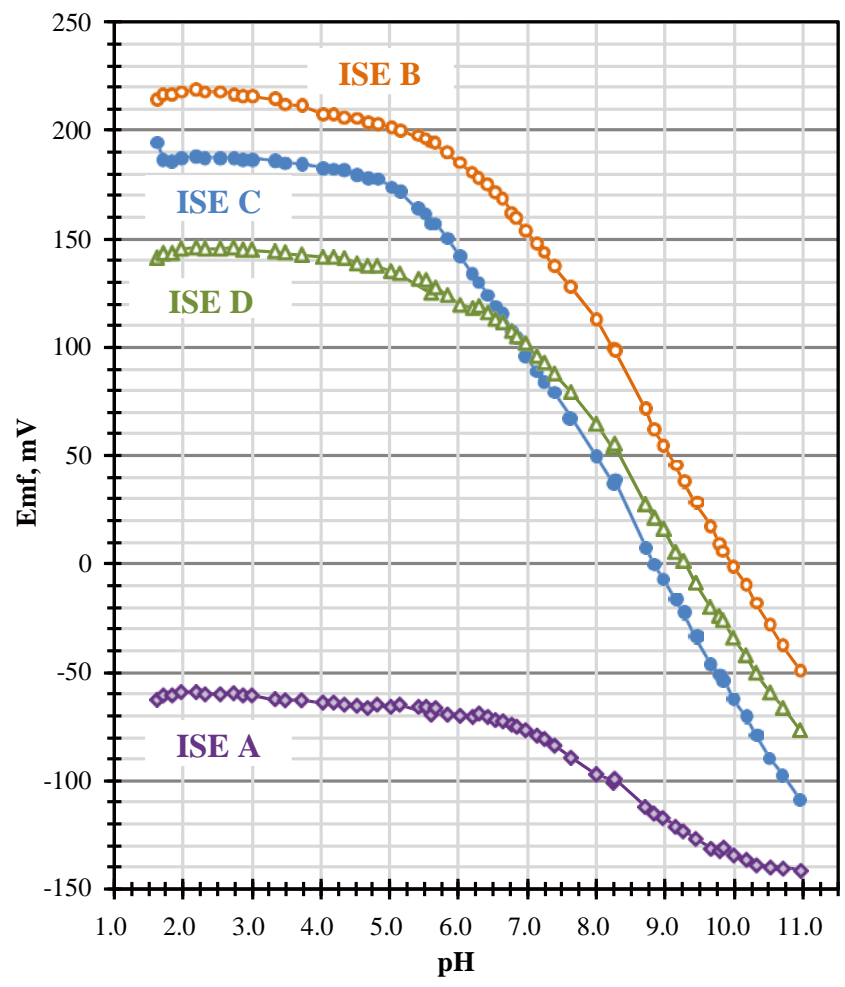

Fig. 2 Reilley diagram plotting the emf of a $1.0 \times 10^{-3} \mathrm{~mol} \mathrm{~L}^{-1} \mathrm{SDZ}$ solution against $\mathrm{pH}$. ISE ion-selective electrode

This behavior was attributed to hydroxyl interference. A slight precipitation of SDZ in solution was observed at extremely acidic $\mathrm{pH}$ values.

As indicated in Table 1, the widest operational $\mathrm{pH}$ range was recorded for the type A detector and the narrowest was recorded for the type $\mathrm{C}$ detector. Compared with the type $\mathrm{A}$ device, the type $\mathrm{B}$ device presented a narrower operational $\mathrm{pH}$ range as a result of a decrease of about $1 \mathrm{pH}$ unit in the upper limit. Compared with the type $\mathrm{B}$ device, the type $\mathrm{C}$ device presented an even narrower operational $\mathrm{pH}$ interval, resulting from a decrease of about $0.5 \mathrm{pH}$ units in both upper and lower limits.

In general, the operational $\mathrm{pH}$ ranges were strongly dependent on the additive, becoming particularly narrow when TOP was used. The presence of TOP enhanced the general operating features but increased the $\mathrm{pH}$ interference at the same time. This corroborated with the fact that TOP improved the potentiometric analytical performance by promoting hydrogen bonding with the analyte. This way, it also acted as a proton exchanger when dissociated as phenolate anion [28]. This feature pointed out the need to buffer the measuring solutions with a pH between 4 and 5.5.

\section{Selectivity}

The selectivity was assessed by the separate solutions method [29]. The emf was measured for two separate solutions: one with only SDZ (of fixed activity) and the other with only interfering ion (and equal activity). Less interference was observed for more negative $\log K^{\mathrm{POT}}$.

The selectivity was examined for several organic and inorganic species of different charges, lipophilicity, and relative molecular mass (Fig. 3). In general, the sensors obeyed the Hofmeister lyotropic anion selectivity sequence, $\mathrm{I}^{-}>\mathrm{NO}_{3}{ }^{-}>\mathrm{Br}^{-}>\mathrm{Cl}^{-}>\mathrm{CH}_{3} \mathrm{COO}^{-}>\mathrm{SO}_{4}{ }^{2-}$, just as expected because the potentiometric response relied on an ionexchange process. This sequence represented the order of extractability of these anions into organic solvents [30], which is mainly governed by differences in hydration energy.

Excluding the effect of iodide and nitrate in ISE types A and $\mathrm{B}$, all species displayed a negligible interference. Membranes with TOP displayed better selectivity than those with no additive or with TOABr. This was attributed to hydrogen bonding between the hydroxyl of the phenol group of TOP and SDZ [31]. Lower interferences were found for ions having small proton affinity. Acetate, citrate, and tartrate showed a similar interfering effect in all electrodes. Despite their high proton affinities, these particular species contributed to significant $\mathrm{pH}$ changes, meaning that the observed interference was a combined effect of their ionized chemical structure and the $\mathrm{H}^{+} / \mathrm{HO}^{-}$ ratio in solution. Furthermore, they have carboxylate groups within the molecular structure that may establish intramolecular hydrogen bonding, which reduces their affinity for intermolecular hydrogen bonding and consequently their degree of interference.

\section{Flow assembly}

A flow-injection manifold operating with a potentiometric detector is typically set up with minimum complexity, requiring only online ionic strength/pH adjustment. That was achieved by a double-channel manifold that alters online the matrix of the injected solutions before they reach the sensor. Under this condition, all solutions were prepared in water and merged online with a supporting electrolyte solution that worked as an ionic strength adjuster (Fig. 1). These solutions were mixed by means of a reactor, assembled in a knitted coil as this configuration minimizes dispersion and ensures adequate mixing of the injected sample and the carrier before they reach the potentiometric cell.

The final FIA assembly was obtained after checking/ setting the several chemical, hydrodynamic, and physical variables indicated in Table 2. A small amount of SDZ was added to the buffer carrier to improve baseline stabilization and increase the lifetime of the detector. The exact SDZ concentration varied and was typically 10 times less than that of the first standard used for calibrating the system. 
Fig. 3 Potentiometric selectivity coefficients $\left(\log K^{\mathrm{POT}}\right)$ obtained in steady-state conditions

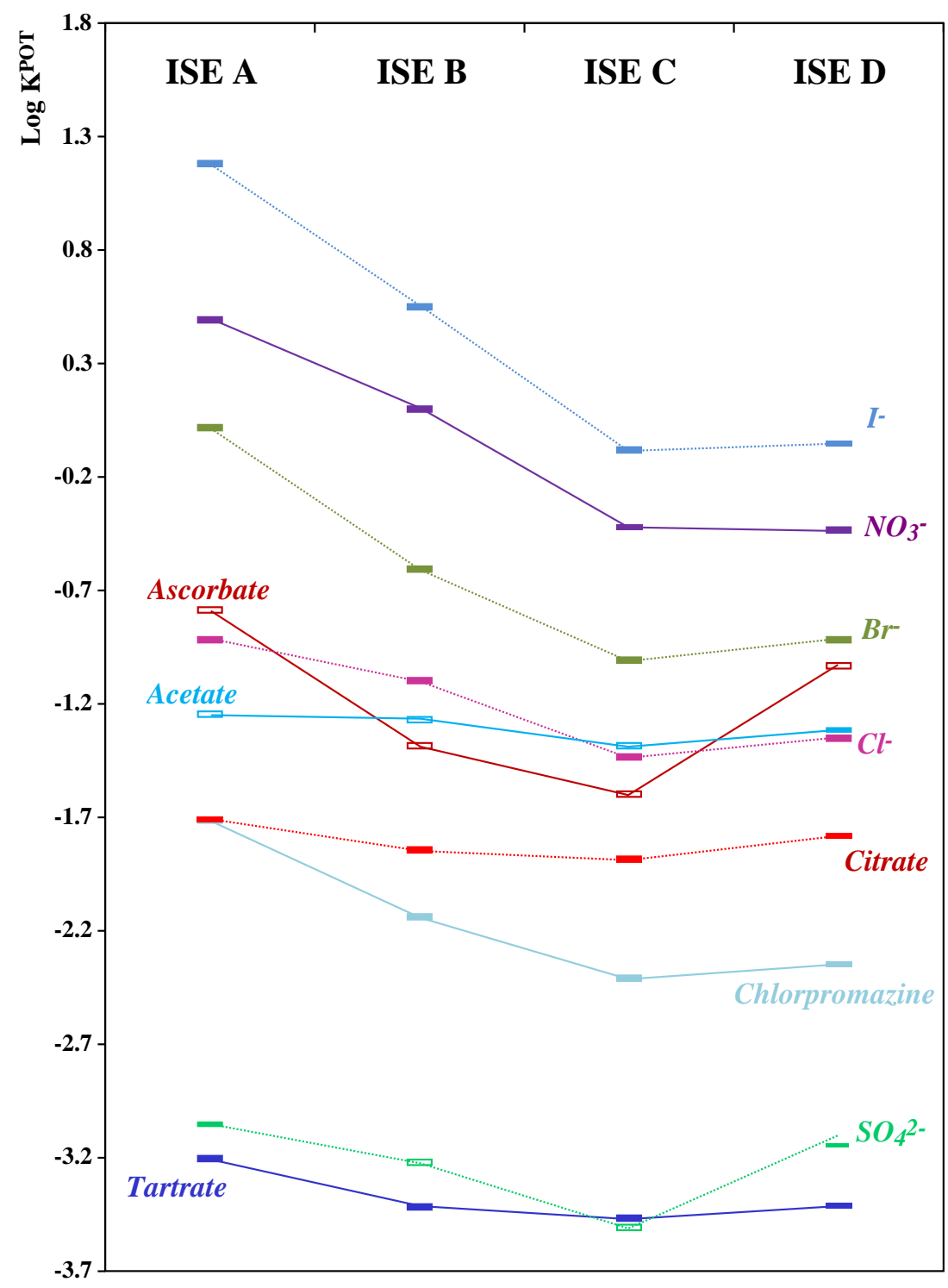

Selection of the sensor length

Their slopes varied within 50 and $62 \mathrm{mV}$ decade ${ }^{-1}$ and the dynamic concentration range was similar to that observed in batch conditions. The longer electrodes were the only ones displaying Nernstian behavior, and these were selected for further studies.
The effect of the electrode contact area was investigated for tubular SDZ sensors of different lengths. Table 3 shows the general operating characteristics of $1.0-$ and $1.5-\mathrm{cm}$ sensors.
Table 2 Selected conditions for the flow-injection potentiometric system

HEPES 4-(2-hydroxyethyl)-1piperazineethanesulfonic acid

\begin{tabular}{llll}
\hline Parameter & Condition & Range studied & Selected conditions \\
\hline Chemical variables & Ionic strength/pH adjuster & - & HEPES, $\mathrm{pH} 4.5$ \\
& Concentration $\left(\mathrm{mol} \mathrm{L}^{-1}\right)$ & - & $1.0 \times 10^{-5}-1.0 \times 10^{-3}$ \\
Hydrodynamic variables & Flow rate $\left(\mathrm{mL} \mathrm{min}^{-1}\right)$ & $2.0-8.0$ & 3.0 \\
& Injection volume $(\mu \mathrm{L})$ & $200-1,000$ & 300 \\
Sensing unit & Length $(\mathrm{mm})$ & 10 and 15 & 15 \\
& Conditioning & - & $1.0 \times 10^{-6} \mathrm{~mol} \mathrm{~L}^{-1} \mathrm{SDZ}$ \\
& Measurement mode & - & Time base \\
\hline
\end{tabular}


Table 3 Main analytical features of the SDZ tubular electrodes with different solid contacts

${ }^{a}$ Relative standard deviation of 18 determinations with three units

${ }^{\mathrm{b}}$ At $4.0 \times 10^{-4} \mathrm{~mol} \mathrm{~L}^{-1}$

${ }^{\mathrm{c}}$ At $4.0 \times 10^{-4} \mathrm{~mol} \mathrm{~L}^{-1}$

${ }^{\mathrm{d}}$ Maximum observed potential deviation in a single calibration

\begin{tabular}{|c|c|c|c|}
\hline \multirow[t]{2}{*}{ Characteristics } & \multirow[t]{2}{*}{ Graphite } & \multicolumn{2}{|l|}{ Metal } \\
\hline & & $1.0 \mathrm{~cm}$ & $1.5 \mathrm{~cm}$ \\
\hline$\overline{\operatorname{LLLR}\left(\mathrm{mol} \mathrm{L}^{-1}\right)}$ & $2.5 \times 10^{-5}$ & $1.0 \times 10^{-5}$ & $1.0 \times 10^{-5}$ \\
\hline $\operatorname{LOD}\left(\mathrm{mol} \mathrm{L}^{-1}\right)$ & $7.6 \times 10^{-6}$ & $3.0 \times 10^{-6}$ & $3.1 \times 10^{-6}$ \\
\hline Slope $\left(\mathrm{mV} \text { decade }^{-1}\right)^{\mathrm{a}}$ & $50.4 \pm 0.3$ & $49.5 \pm 0.9$ & $61.6 \pm 1.2$ \\
\hline$R^{2}$ & $0.994 \pm 0.004$ & $0.996 \pm 0.003$ & $0.996 \pm 0.001$ \\
\hline Repeatability $(\mathrm{mV})^{\mathrm{b}}$ & \pm 0.8 & \pm 0.8 & \pm 0.2 \\
\hline Reproducibility $(\mathrm{mV})^{\mathrm{c}}$ & \pm 3.5 & \pm 2.4 & \pm 1.6 \\
\hline Precision $(\%)$ & 3.5 & 2.5 & 2.5 \\
\hline Accuracy $(\%)$ & 2.2 & 3.0 & 1.3 \\
\hline Baseline drift (mV) & $<5.0$ & $<5.0$ & $<5.0$ \\
\hline Baseline stability $(\mathrm{mV})^{\mathrm{d}}$ & $<0.7$ & $<0.7$ & $<0.7$ \\
\hline Sampling rate $\left(\right.$ sample $\left.\mathrm{h}^{-1}\right)$ & $\sim 80$ & $\sim 82$ & $\sim 84$ \\
\hline
\end{tabular}

Because of the transient signal, the response time is lower for detectors of shorter length because the time of contact between the selective membrane and the analyte is limited to the size of the electrode. However, the sampling rates were about 80 samples per hour for all lengths tested. This was most probably a result of the quick response of the sensors, taking only a few seconds to reach a stable potential.

Selection of the main flow variables

The most relevant flow variables were the sampling volume and the flow rate. This optimization process was performed by investigating the effect of these variables on the slope and sampling frequency of six SDZ standard solutions, from $1.0 \times 10^{-4}$ to $1.0 \times 10^{-2} \mathrm{~mol} \mathrm{~L}^{-1}$.

Injection volume

In general, the FIA peaks were higher for increasing injection volumes, meaning the detector had higher sensitivity. However, the residence time of the sample in the electrode surface was also longer, leading to a longer time to return to the baseline (and hence smaller sampling rates) and greater consumption of sample/buffer. Thus, a compromise between these two opposite effects was sought for $200-, 500-$, or $1,000-\mu \mathrm{L}$ injection volumes. For the maximum injected volume (corresponding to about $2 \mathrm{~m}$ of FIA tube), the steady state was obtained regardless of the flow rate used. Theoretical slopes were obtained after $500 \mu \mathrm{L}$ (Table 4). Above this, the peak heights increased slightly but had no significant effect on the slope of the calibration run and provided dispersion values close to 1 . This condition ensured a small dispersion, corresponding always to peaks higher than $90 \%$ of the maximum peak height obtained, less time to reach the baseline, and less reagent consumption. The average sampling rate was 84 samples per hour. For higher injected volumes, the average sampling rate decreased by $8 \%$ and the average sample consumption increased by $35 \%$.

Flow rate

For a constant injected volume, the residence time of the sample is inversely proportional to the flow rate and the recovery time increases with the residence time of the sample. Thus, higher sampling rates are expected for higher flow rates, but this condition may hinder sensitivity. A compromise between these two features was checked from 2 to $8 \mathrm{~mL} \mathrm{~min}^{-1}$. The flow rates of each single channel were

Table 4 Analytical response of the SDZ tubular sensors of $1.5-\mathrm{cm}$ length (dispersion calculated for $5 \times 10^{-4} \mathrm{~mol} \mathrm{~L}^{-1}$ )

\begin{tabular}{lllll}
\hline $\begin{array}{l}\text { Loop } \\
(\mu \mathrm{L})\end{array}$ & $\begin{array}{l}\text { Flow rate } \\
\left(\mathrm{mL} \mathrm{min}^{-1}\right)\end{array}$ & $\begin{array}{l}\text { Slope } \\
(\mathrm{mV} \mathrm{decade}\end{array}$ & $\begin{array}{l}\text { Sampling rate } \\
\left(\text { samples }^{-1}\right)\end{array}$ & $\begin{array}{l}\text { Dispersion } \\
\text { coefficient }\end{array}$ \\
\hline 200 & 2 & $44.1 \pm 0.8$ & $48 \pm 0$ & 1.4 \\
& 4 & $61.2 \pm 3.5$ & $79 \pm 15$ & 1.4 \\
& 6 & $55.1 \pm 0.8$ & $111 \pm 0$ & 2.4 \\
& 8 & $49.7 \pm 0.7$ & $152 \pm 11$ & 2.8 \\
500 & 2 & $52.2 \pm 3.7$ & $32 \pm 3$ & 1.2 \\
& 4 & $65.4 \pm 0.3$ & $82 \pm 4$ & 1.2 \\
& 6 & $65.7 \pm 2.2$ & $112 \pm 6$ & 1.5 \\
& 8 & $61.8 \pm 2.1$ & $144 \pm 0$ & 2.4 \\
1,000 & 2 & $59.9 \pm 1.2$ & $27 \pm 1$ & 1.1 \\
& 4 & $59.6 \pm 0.8$ & $49 \pm 8$ & 1.2 \\
& 6 & $52.6 \pm 3.2$ & $67 \pm 2$ & 1.3 \\
& 8 & $52.7 \pm 2.2$ & $90 \pm 0$ & 1.4 \\
\hline
\end{tabular}


set equal by keeping the same pumping tubes on the peristaltic pump and the total flow rate was measured after the detector. SDZ sensors displayed near-Nernstian slopes for flow rates of $3 \mathrm{~mL} \mathrm{~min}^{-1}$ and above and these remained more or less constant after that (Table 4). Under this flowrate range, the peaks became sharper and had higher resolution. Thus, the flow rate was set to $3.0 \mathrm{~mL} \mathrm{~min}$. About $90 \%$ of the maximum peak height was found to reach the baseline within a short time and less carrier was consumed. The sampling rate was about 84 samples per hour. For higher injected volumes, the sampling rate decreased by $9 \%$ and the sample consumption increased by $40 \%$.

\section{Main analytical features}

The main analytical features of the $1.5-\mathrm{cm}$ metal electrodes were similar to those obtained in batch conditions. This observation indicated that the selective membrane governed the analytical response of the devices, regardless of the solid contact used. For comparison purposes, a tubular graphite-based solid-contact electrode of 1.0-cm length (Fig. 1) was also constructed and compared with the novel metal configuration, also of $1.0-\mathrm{cm}$ length (Table 3 ). No significant differences were obtained in terms of calibration parameters, selectivity, and $\mathrm{pH}$ effect, thus confirming that the observed behavior was attributed to the selective membrane. These electrodes were, however, less sensitive than those of $1.5-\mathrm{cm}$ length, which could be straightly correlated to the effective contact time between the sample plug and the membrane, which is greater for long electrodes.

The metal electrodes of $1.5-\mathrm{cm}$ length were selected for

further studies. These were the only ones displaying Nernstian behavior. An extended calibration is shown in Fig. 4.

\section{Lifetime and precision}

The electrode lifetime was investigated by testing periodically SDZ solutions ranging from $1.0 \times 10^{-4}$ to $1.0 \times 10^{-2} \mathrm{~mol} \mathrm{~L}^{-1}$. The electrodes exhibited good stability in terms of slope, with negligible changes after 2 months of continuous use. The repeatability of the emf was $1.1 \%$ for a $4.0 \times 10^{-4} \mathrm{~mol} \mathrm{~L}^{-1}$ SDZ standard solution $(n=15)$.

The precision of the method was investigated by intraday and interday determination of SDZ with three different concentrations and was determined by calculating the relative standard deviation (Table 5). For intraday studies, each concentration was evaluated by five repeated measurements for five times in a working day. For interday measurements, studies were conducted for 1 week. No significant differences were found between intraday and interday assays. The variation coefficients ranged from 0.7
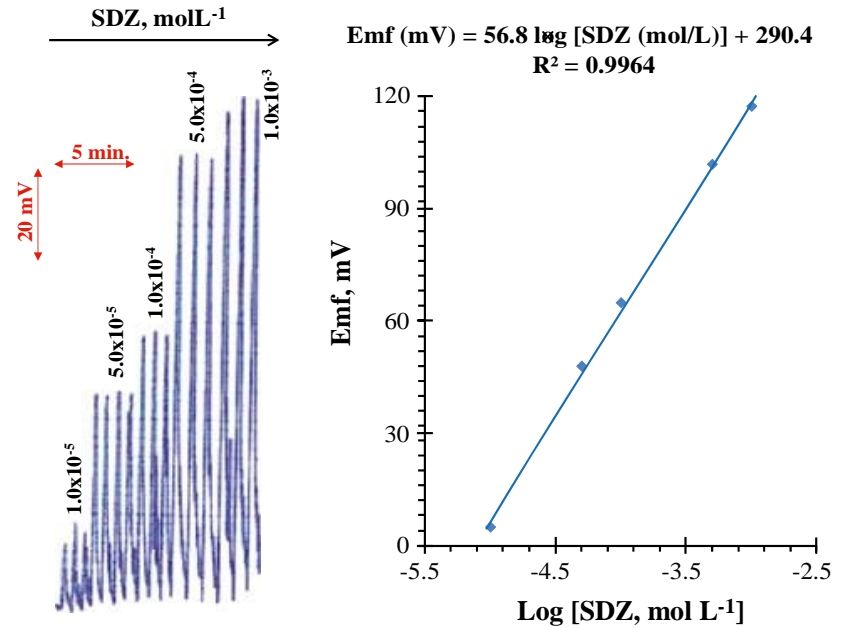

Fig. 4 Typical diagram obtained with $1.5-\mathrm{cm}$ stainless steel electrodes and the corresponding calibration curve $\left(1.0 \times 10^{-6} \mathrm{~mol} \mathrm{~L}^{-1} \mathrm{SDZ}\right.$ flowing with the carrier buffer)

to $8.7 \%$, thus confirming the high precision of the potentiometric readings.

The accuracy was assessed by estimating the percentage relative error between measured and added concentrations. Relative errors were always less than $10 \%$ and the recoveries ranged from 93.1 to $104.6 \%$ (Table 5), confirming the accuracy of the method.

Analysis of aquaculture waters

The applicability of the SDZ electrodes was tested in aquaculture waters collected from commercial fish farms in the north region of Portugal. Estimating the levels of SDZ in polluted waters from aquaculture facilities was not possible for two main reasons: (1) there is no legal limit for SDZ in aquaculture use and (2) the effective concentration depends on the time of sampling after drug administration, which in turn depends on the purpose of its use (different doses for different fish conditions). Indeed, it is quite probable that on many occasions the system will be unable to perform a direct reading of the drug. In this case, the use of solid-phase microextraction techniques is advised. They allow a significant preconcentration of SDZ and, at the same time, contribute to sample cleanup.

All assays were conducted in (1) batch conditions with the conventional-shape graphite-based solid-contact electrodes and in (2) flow conditions with tubular metal electrodes of 1.5-cm length. Type $\mathrm{C}$ membranes were always used for this purpose. Table 6 reports the mean results of at least five determinations. In batch experiments, average recoveries and the corresponding relative standard deviations were $101.4 \%$ and $3.7 \%$, respectively. For FIA mode, these were $102.7 \%$ and $2.0 \%$, respectively. 
Table 5 Analytical precision and accuracy of the assay of SDZ with flow-injection analysis (FIA)

\begin{tabular}{|c|c|c|c|c|c|c|c|c|}
\hline \multirow[t]{2}{*}{ Concentration $\left(\mathrm{mmol} \mathrm{L}^{-1}\right)$} & \multicolumn{4}{|l|}{ Intraday $^{\mathrm{a}}$} & \multicolumn{4}{|l|}{ Interday ${ }^{\mathrm{b}}$} \\
\hline & Found $\left(\mathrm{mmol} \mathrm{L}^{-1}\right)$ & Recovery (\%) & $\delta(\%)$ & $\mathrm{VC}(\%)$ & Found $\left(\mathrm{mmol} \mathrm{L}^{-1}\right)$ & Recovery (\%) & $\delta(\%)$ & $\mathrm{VC}(\%)$ \\
\hline 0.16 & 0.17 & 104.6 & 4.4 & 8.7 & 0.16 & 100.7 & 0.0 & 5.5 \\
\hline 1.00 & 0.94 & 93.7 & -6.3 & 2.7 & 0.93 & 93.1 & -7.0 & 0.7 \\
\hline
\end{tabular}

Recovery $(\%)=[\mathrm{SDZ}]_{\text {found }} /[\mathrm{SDZ}]_{\text {added }} \times 100 ; \delta(\%)=\left([\mathrm{SDZ}]_{\text {found }}-[\mathrm{SDZ}]_{\text {added }}\right) /[\mathrm{SDZ}]_{\text {added }} \times 100 ;$ variation coefficient $(\%)=$ standard deviation $/$ $[\mathrm{SDZ}]_{\text {mean found }} \times 100$

$V C$ variation coefficient

${ }^{a}$ Average of five measurements in 1 day

${ }^{\mathrm{b}}$ Average of five measurements in 1 week

The potentiometric set of results was validated by LCMS/MS procedures. Good agreement was found between added and found amounts of SDZ. The results showed recoveries ranging from 96 to $107 \%$, which corresponded to relative errors within -4.1 and $+6.7 \%$. The Student $t$ test confirmed no significant differences between the means of added amounts of potentiometric and chromatographic procedures. The $p$ value was 0.033 and 0.72 for batch and FIA analysis, always below the critical value (1.8).

Each calibration procedure with seven standards required approximately $30 \mathrm{~mL}$ of HEPES buffer and less than $1 \mathrm{~mL}$ of each standard solution (considering three injections per standard). At least five diluted samples may be analyzed without recalibration.

The environmental effects of the discharged effluents were considered to be negligible. They contain only buffer and SDZ (at $7.8 \mu \mathrm{g} \mathrm{mL}^{-1}$ ). Still, for safety purposes, it is advisable to remove SDZ or make it inactive against microbes. The first suggestion may be achieved by its adsorption in activated carbon or its removal by extraction into solid-phase extraction cartridges. The second choice could be complete oxidation with a strong oxidant, such as permanganate. This latter case should be avoided because of the introduction of additional toxicants. It should also be coupled with ecotoxicity assays to ensure low biological toxicity of the oxidation products. The total volume of effluent is also quite low, producing an average of $180 \mathrm{~mL}$ per hour.

\section{Conclusions}

The sensor performance was favored by a high dielectric constant mediator solvent, improving the slope, lower limit of the linear range, and reproducibility. TOP was found to be essential to improve the detector sensitivity, but
Table 6 Batch and FIA potentiometric determination of SDZ in aquaculture water samples $(n=5)$ and comparison with the liquid chromatographytandem mass spectrometry (LC-MS/MS) method

\begin{tabular}{|c|c|c|c|c|c|c|c|}
\hline \multirow[t]{2}{*}{ Sample } & \multirow[t]{2}{*}{ Added $\left(\mu \mathrm{g} \mathrm{mL}^{-1}\right)$} & \multicolumn{3}{|c|}{ Found $\left(\mu g \mathrm{~mL}^{-1}\right)$} & \multicolumn{3}{|c|}{ Recovery( \%) } \\
\hline & & Batch & FIA & LC-MS/MS & Batch & FIA & LC-MS/MS \\
\hline \multirow[t]{2}{*}{1} & 30.0 & 31.8 & 30.8 & 31.5 & 106.0 & 102.7 & 102.7 \\
\hline & 140.2 & 141.4 & 141.4 & 145.0 & 100.9 & 100.9 & 100.9 \\
\hline \multirow[t]{2}{*}{2} & 30.0 & 31.3 & 30.3 & 29.9 & 104.3 & 101.0 & 101.0 \\
\hline & 140.2 & 134.9 & 143.4 & 142.0 & 96.2 & 102.3 & 102.3 \\
\hline \multirow[t]{2}{*}{3} & 30.0 & 31.8 & 31.3 & 32.3 & 106.0 & 104.3 & 104.3 \\
\hline & 140.2 & 144.2 & 147.4 & 145.6 & 102.9 & 105.1 & 105.1 \\
\hline \multirow[t]{2}{*}{4} & 30.0 & 32.0 & 31.0 & 32.1 & 106.7 & 103.3 & 103.3 \\
\hline & 140.2 & 140.7 & 144.7 & 143.9 & 100.4 & 103.2 & 103.2 \\
\hline \multirow[t]{2}{*}{5} & 30.0 & 29.8 & 31.3 & 30.8 & 99.3 & 104.3 & 104.3 \\
\hline & 140.2 & 138.2 & 141.9 & 140.7 & 98.6 & 101.2 & 101.2 \\
\hline \multirow[t]{2}{*}{6} & 30.0 & 30.3 & 29.5 & 30.5 & 101.0 & 98.3 & 98.3 \\
\hline & 140.2 & 134.4 & 148.2 & 144.6 & 95.9 & 105.7 & 105.7 \\
\hline
\end{tabular}


enhanced the $\mathrm{pH}$ interference. In general, SDZ sensors using oNFOE as a mediator solvent and TOP provided a rapid, sensitive, inexpensive, and reliable method for SDZ determination in aquaculture waters with minimal sample pretreatment.

The proposed FIA method displayed excellent reproducibility, a high sampling rate, a wide linear range, a low detection limit, high sensitivity, and good selectivity. Moreover, the overall method required a low level of operator intervention and produced low volumes of effluents. The proposed system is accurate, precise, inexpensive regarding reagent consumption and the equipment involved, and simple, and is adequate for routine procedures. Furthermore, it can be easily applied to the automation of routine determination of SDZ in real samples.

Acknowledgements The authors acknowledge financial support from FCT, Fundação para a Ciência e Tecnologia/FEDER by means of project PTDC/AGR-AAM/68359/2006 and a PhD grant to S.A.A. A. (SFRH/BD/42509/2007).

\section{References}

1. Boxall ABA, Fogg LA, Blackwell PA, Kay P, Pemberton EJ, Croxford A (2004) Rev Environ Contam Toxicol 180:1-91

2. Sørensen LK, Elbæk TH (2004) Chromatographia 60:287-291

3. Cabello FC (2006) Environ Microbiol 8:1137-1144

4. Maki T, Hirono I, Kondo H, Aoki T (2008) J Fish Dis 31:461-468

5. Akinbowale OL, Peng H, Barton MD (2006) J Appl Microbiol 100:1103-1113

6. Cañada-Cañada F, Muñoz de la Peña A, Espinosa-Mansilla A (2009) Anal Bioanal Chem 395:987-1008

7. Romero-González R, López-Martínez JC, Gómez-Milán E, Garrido-Frenich A, Martínez-Vidal JL (2007) J Chromatogr B 857:142-148

8. Croubels S, Wassink P, Backer P (2002) Anal Chim Acta 473:183-194

9. Balakrishnan VK, Terry KA, Toito J (2006) J Chromatogr A 27:1-10
10. Bienenmann-Ploum M, Korpimäki T, Haasnoot W, Kohen F (2005) Anal Chim Acta 529:115-122

11. Chafer-Pericas C, Maquieira A, Puchade R, Miralle J, Moreno A (2010) Anal Bioanal Chem 396:911-921

12. Kamel AH, Almeida SAA, Sales MGF, Moreira FTC (2009) Anal Sci 25:365-371

13. Almeida SAA, Heitor AM, Montenegro MCBSM, Sales MGF (2011) Sulfadiazine-selective determination in aquaculture environment: selective potentiometric transduction by neutral or charged ionophores. Talanta 85:1508-1516. doi:10.1016/ j.talanta.2011.06.022

14. Lima JL, Montenegro MC, Sales MG (1996) J Pharm Biomed Anal 14:931-938

15. Yang X, Hibbert DB, Alexander PW (1988) Anal Chim Acta 372:378-398

16. Alexander PW, Dimitrakopoulos T, Hibbert DB (1998) Electroanalysis 10:707-712

17. Ceresa A, Sokalski T, Pretsch E (2001) J Electroanal Chem 501:70-76

18. Vamvakaki M, Chaniotakis NA (1996) Anal Chim Acta 320:5361

19. Buck RP, Lindner E (1994) Pure Appl Chem 66:2527-2536

20. Buck RP, Cosofret VV (1993) Pure Appl Chem 65:1849-1858

21. Fitzer E, Kochling KH, Boehm HP, Marsh H (1975) Pure Appl Chem 67:473-506

22. Ribeiro CMF, Matos CD, Sales MGF, Vaz MCVF (2002) Anal Chim Acta 471:41-49

23. Aubeck R, Brauchle C, Hampp N (1991) Analyst 116:811-814

24. Eugster R, Rosatzin T, Rusterholz B, Aebersold B, Pedrazza U, Rüegg D, Schmid A, Spichiger UE, Simon W (1994) Anal Chim Acta 289:1-13

25. Poursaberi T, Hosseini M, Taghizadeh M, Pirelahi H, Shamsipur M, Ganjali MR (2002) Microchem J 72:77-83

26. Dielectric constant reference guide. http://www.asiinstr.com/ technical/Dielectric\%20Constants.htm\#Section\%20D. Accessed 30 Jun 2011

27. Bakker E, Pretsch E (2005) Trends Anal Chem 24:199-207

28. Hara H, Okazaki S, Fujinaga T (1980) Anal Chim Acta 121:119123

29. Umezawa Y, Bühlmann P, Umezawa K, Tohda K, Amemiya S (2002) Pure Appl Chem 72:1851-2082

30. Wegmann D, Weiss H, Ammann D, Morf WE, Pretsch E, Sugahara K, Simon W (1984) Mickrochim Acta 1-16

31. Fujinaga T, Okazaki S, Hara H (1978) Chem Lett 11:12011202 